\title{
Australian Sojourn
}

\section{Working in a Community Mental Health Clinic in Melbourne}

\author{
StEPHEN P. ReILly, Senior Registrar, Gaskell House, Manchester Royal Infirmary
}

Community psychiatry means different things to different people. Since the 1970 s the American model of community psychiatry based on mental health clinics has attracted heavy criticism, whilst the UK concept of rooting community psychiatric services firmly within primary health care has gained increasing support.' The need for community-orientated psychiatric services is generally agreed upon but definition of community and the mode of delivery are not. In Australia both free and private health care are available; community health centres and community mental health clinics exist (sometimes literally) side by side.

Here, based on my own experience of working in a Melbourne community mental health clinic from October 1982 to September 1983, I try to present a clear picture of the ideology and practice of one particular clinic.

\section{Development of community mental health clinics}

The establishment of free community mental health clinics in Victoria arose out of a concern for a comprehensive, community-orientated health service.

Through a combination of political and financial circumstances in the early $70 \mathrm{~s}$, the birth of the community health programme was induced, as it were, leaving little time for details of planning. One result was that health centres and mental health clinics sprang up in response to organized local demand rather than need. Currently there are over twenty mental health clinics in Victoria, many of which function without an on-site staff psychiatrist, a situation partly due to the waning popularity of the posts.

Although the Victorian system of community mental health care is loosely founded on the American model, the state's organization of health services administration is changing, bringing its own impetus to the further modification of the community health services.

The clinic described below was opened in 1975 and is one of the oldest in the state.

\section{The Heidelberg Clinic \\ Structure and staffing}

The clinic runs from converted shop premises set in a shopping precinct in West Heidelberg, North Melbourne, and consists of a reception area/office (housing medical records and pharmacy), six interviewing rooms, a common room and a kitchen. There are two cars on loan from the Health Commission for staff use. During my time at the clinic staffing comprised one psychiatrist, two psychiatric nurses, a social worker, an occupational therapist, two clerical staff and a case-aide.

The clinic comes under the jurisdiction of a local mental hospital (Plenty) which has administrative responsibility and control of government funds ear-marked for the community service. West Heidelberg provides approximately 40 per cent of all clinic referrals and is predominantly a working class area with the usual admixture of psychiatric and social problems. However, the total catchment area covers $395 \mathrm{sq} \mathrm{km}$ and has a population of 155,000 living in urban, sub-urban and rural districts. The great majority of people are white, Australian born with a small minority of immigrant British and other Europeans.

\section{Ideology}

Consultations and drugs are free of charge and the emphasis is on easy accessibility of services. There is free tea and coffee on a 'drop-in' basis, new clients can be seen without a formal referral, home visits arranged and local caring agencies are encouraged to use the resources of clinic expertise. Having said that, there are limits. The clinic is open from $9 \mathrm{am}$ to $5 \mathrm{pm}$, Monday to Friday. Outside these times a telephone answering service directs callers to local hospitals for help. Surprisingly, this arrangement causes little inconvenience to clients, most of whom manage to contain problems until clinic staff are available. In fact, there is a valuable therapeutic communication inherent in this system; namely, that total dependence on the clinic is not possible. Both self-help and responsibility for self are an essential part of any treatment plan.

The range of clients is very broad and the work cuts across the usual sub-specialties of psychiatry. It includes dealing with disturbed children, adolescents, families, the whole gamut of adult psychiatric disorders, psychogeriatrics, medico-legal problems, social problems and, occasionally, mental handicap. Specialist services are available in surrounding hospitals.

All clinical staff have commitments to the community on three levels. On the primary level each therapist carries his or her own case-load of clients. Secondary level commitments involve giving advice and support to outside therapists with regard to specific clients of their own. Responsibilities on a tertiary level include giving time to the development of health care and welfare in the community. This incorporates the concept of preventive work which, as yet, is not easily applied in the sphere of psychiatry.

Linked in with this system is the basic tenet that each staff member acquires general skills applicable to the assessment and management of clients in addition to the specialist skills appropriate to that staff member's particular discipline. In consequence each staff member carries a wide range of clients, though usually with a bias toward personal interests and sphere of expertise. Should medication be required, the psychiatrist's involvement is obligatory.

Informal advice and support within the staff network are freely available and a weekly meeting provides a forum for case presentations, discussion of clinical problems and 
re-allocation of clients, as well as up-dating on community activities, discussion of policy and administration and airing staff problems.

\section{Primary consultations}

Approximately 50 per cent of clients have a diagnosis of psychiatric disorder, many of whom are referred for follow-up by the parent mental hospital. The remaining 50 per cent present with personal, marital or family problems which may include financial or legal difficulties.

In the financial year from July 1982 to June 1983 there was a total of 4,050 attendances including 229 new referrals. The age range covered 3 per cent between nought and nine years; 14 per cent between ten and nineteen; 81 per cent between twenty and sixty-nine; and 2 per cent between seventy and eighty-nine.

Self-referrals accounted for 35 per cent of new clients; the rest were referred by mental hospitals, private psychiatrists, GPs, other health and welfare centres, schools, colleges, the police and other community agencies.

\section{Secondary consultation}

Commitments at a secondary level depend upon the interests and skills of staff members.

As psychiatrist I took over established contacts with a Health and Welfare Centre in a neighbouring shire and a local Old Persons Home. The social worker had active involvement with local schools and the Infant Welfare Centre. Nursing staff offered support to the special accommodation houses for the chronic mentally ill, whilst the occupational therapist was especially interested in agencies providing day care for the elderly and work experience for the chronic patients.

There was also a close working relationship with the local Health and Welfare Centre which houses GPs, social workers, dentists, financial and legal counsellors. The liaison grew rapidly and proved to be extremely fruitful for clinics and clients alike.

\section{Tertiary consultation}

The inter-agency links give ample opportunity for crossfertilization of ideas and the discussion of important community issues. In addition, many contacts have been forged by clinic staff over the years including links with schools, colleges, police, citizens' advice bureaux, day centres, sheltered workshops, churches and hospitals. There is a formal teaching component in the form of clinic placements for social work students, counselling psychology students and student nurses. Unfortunately there is no opportunity for local psychiatrists in training to work on placement at the clinic.

\section{Comment}

The pace is fast in community psychiatry and the Heidelberg Clinic has changed over the past year. Working methods and ideology depend, in part, upon the personalities and views of staff. But, for me, working there was like a breath of fresh air. The work was demanding and called for a wide range of knowledge and skills. I had to further develop my clinical acumen and administrative skills quickly in order to cope effectively and, to my surprise, found this challenge thoroughly enjoyable. The clinic staff were very generous and helped greatly in all this.

Along with the rest of the staff I was very busy during the day time but there were no evening or week-end on call duties. The salary was very generous by UK standards and the Australian life-style attractive. I consider that I learned a great deal about community aspects of psychiatry which I could not have got from a purely British based training and, of course, there was all the fun and freshness of life in a new country.

The 'shop front' clinic provides opportunities for destigmatizing psychiatry in a way that departments of psychiatry in district general hospitals never can. Changing the system to allow self-referral greatly increases the accessibility of services and the provision of clinic cars for staff use adds to the availability of expert help in the community. This is all very different in spirit from the grudging assessment of self-referred patients in casualty by overworked and inexperienced junior psychiatrists, and the expensive 10-minute domiciliary visit by the consultant on his way home.

I suppose I could have found a community psychiatry training post in this country and learned how to treat acutely psychotic patients in their own homes, assess family pathology, hold a multidisciplinary team together and deal with clinic administrative matters. But I do not believe I would have had the responsibilities or the free hand that I had in Melbourne, nor the opportunity to treat children, the very old and deal with forensic cases; all valuable training experience. As a trainee it is important to establish a broad base on which to build and experience working overseas is one way of enriching one's own postgraduate training.

To go back to my own experience, perhaps I should say that, contrary to what you might think after reading this article, I was not wearing rose-tinted spectacles during my stay in Australia! This approach to community psychiatry is not without its problems and its future is far from assured. ${ }^{2}$

Paradoxically, working in the community can be very lonely and sometimes the responsibilities seem to outweigh the satisfaction. It is difficult to find time to do research and attend conferences. Yet, for me, the year in Melbourne was a key training experience. Now it seems very clear to me that despite the problems, easily accessible psychiatric centres based in the community for the community should be an essential component for any area psychiatric service which claims to provide comprehensive care. It is equally clear that the model of care instituted should fulfil the needs of the community; not vice-versa.

\section{ACKNOWLEDGEMENTS}

My thanks to Dr H. S. Paull (former Superintendent of Plenty Hospital) and all the staff of The Heidelberg Clinic. for their help and support during my stay in Australia.

\section{References}

IClare, A. W. (1980) Community mental health centres. Journal of the Royal Society of Medicine, 73, 75-76.

2Donovan, C. M. (1982) Problems of psychiatric practice in Community Mental Health Centres. American Journal of Psychiatry, 139, 456-460. 